\title{
Specific of Stable Carbon Isotopes Determination in Organic-Bearing Sediments
}

\author{
Elena V. Lazareva, Viktor A. Ponomarchuk, \\ Sergey M. Zhmodik, Ivan S. Kirichenko, \\ Alexander N. Pyryaev and Tatiana N. Moroz \\ Sobolev Institute of Geology and Mineralogy SB RAS \\ Novosibirsk, Russian Federation
}

Received 10.06.2021, received in revised form 03.08.2021, accepted 20.08.2021

\begin{abstract}
The study of the carbon isotopic composition in organic-bearing bottom sediments of the thermal lake Fumarolnoye (Uzon caldera, Kamchatka) has been carried out. The results of studying $\delta^{13} \mathrm{C}$ changes in the bottom sediments of a thermal lake during the sequential extraction of $\mathrm{H}_{3} \mathrm{PO}_{4}$ for 2 hours, 24 hours and 7 days are presented. The change in $\delta^{13} \mathrm{C}$ with time and after treatment with $\mathrm{HCl}$ and $\mathrm{H}_{2} \mathrm{O}_{2}$ is shown using two samples as an example. After treatment with $\mathrm{HCl}$, the $\delta^{13} \mathrm{C}$ values change relative to the initial ones from 1 to $3 \%$, which can be taken into account when interpreting the data. The standard procedure for removing carbonate with hydrogen peroxide reveals a significant transformation of the residual C-containing substance in the case of a prolonged reaction with $\mathrm{H}_{3} \mathrm{PO}_{4}$ at elevated temperatures.
\end{abstract}

Keywords: stable carbon isotopes, organic-containing bottom sediments, peat, thermal reservoir, Uzon caldera, Kamchatka.

Citation: Lazareva E. V., Ponomarchuk V. A., Zhmodik S. M., Kirichenko I. S., Pyryaev A. N., Moroz T. N. Specific of stable carbon isotopes determination in organic-bearing sediments, J. Sib. Fed. Univ. Chem., 2021, 14(3), 418-432. DOI: 10.17516/19982836-0251

(C) Siberian Federal University. All rights reserved

This work is licensed under a Creative Commons Attribution-NonCommercial 4.0 International License (CC BY-NC 4.0).

* Corresponding author E-mail address: lazareva@igm.nsc.ru 


\title{
Особенности определения стабильных изотопов углерода в органосодержащих осадках
}

\author{
Е. В. Лазарева, В.А. Пономарчук, С. М. Жмодик, \\ И. С. Кириченко, А. Н. Пыряев, Т.Н. Мороз \\ Институт геологии и минералогии им. В. С. Соболева СО РАН \\ Российская Федерация, Новосибирск
}

\begin{abstract}
Аннотация. Проведено исследование изотопного состава углерода в органосодержащих донных осадках термального озера Фумарольное (кальдера Узон, Камчатка). Представлены результаты изучения изменений $\delta^{13} \mathrm{C}$ в донных осадках термального озера при последовательном разложении $\mathrm{H}_{3} \mathrm{PO}_{4}$ в течение 2 ч, 24 ч и 7 дней. На примере двух образцов показано изменение $\delta^{13} \mathrm{C}$ во времени и после обработки $\mathrm{HCl}$ и $\mathrm{H}_{2} \mathrm{O}_{2}$. После обработки $\mathrm{HCl}$ значения $\delta^{13} \mathrm{C}$ изменяются относительно исходных от 1 до $3 \%$, что можно учесть при интерпретации данных. При стандартной процедуре удаления карбоната перекисью водорода выявляется существенная трансформация остаточного С-содержащего вещества в случае длительной реакции с $\mathrm{H}_{3} \mathrm{PO}_{4}$ при повышенных температурах.
\end{abstract}

Ключевые слова: стабильные изотопы углерода, органосодержащие донные осадки, торф, термальный водоем, кальдера Узон, Камчатка.

Цитирование: Лазарева, Е.В. Особенности определения стабильных изотопов углерода в органосодержащих осадках / Е. В. Лазарева, В. А. Пономарчук, С. М. Жмодик, И. С. Кириченко, А. Н. Пыряев, Т. Н. Мороз // Журн. Сиб. федер. ун-та. Химия, 2021, 14(3). С. 418-432. DOI: 10.17516/1998-2836-0251

\section{Введение}

В геохимических процессах углерод, находясь в окисленном и восстановленном состояниях, играет значимую роль. Соотношение между этими формами изменчиво и зависит от окружающей обстановки и физико-химических параметров.

Известные аналитические методы $[1,2]$ предполагают раздельное определение изотопного состава углерода в карбонатах и органическом веществе. Анализ в первом случае заключается

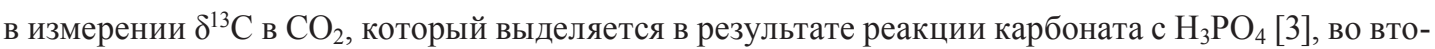
ром - в $\mathrm{CO}_{2}$, выделившемся в результате окисления органических соединений кислородом [1]. Для корректности аналитических данных необходимо предварительное разделение находящихся в образце исходных форм. Впервые на проблему пробоподготовки карбоната было обращено внимание еще в 1953 г. [4] в связи с контаминацией изотопного состава биогенного карбоната, присутствующей в образце изотопами органического углерода. Позднее проведены многочисленные исследования влияния органического материала на вариации $\delta^{13} \mathrm{C}$ и $\delta^{18} \mathrm{O}$ в карбонатах после «очистки» карбоната от органики различными способами (обработка температурой, холодной плазмой, $\mathrm{H}_{2} \mathrm{O}_{2}, \mathrm{NaOCl}$ и т. д.) и на вариации $\delta^{13} \mathrm{C}$ в органическом веществе после «очистки» от присутствующего карбоната кислотной обработкой $[5,6]$.

$$
-419-
$$


Задача удаления органического вещества, находящегося в нефтематеринских породах, углях, донных отложениях, торфах, почвах и т. д., наиболее трудна из-за химического строения органического вещества. Современные органосодержащие отложения содержат водорастворимые, легко- и трудногидролизуемые органические соединения, битумы, целлюлозу и т. д. [7-9]. $\mathrm{HCl}$, наиболее часто применяемый реагент для растворения карбонатов, используется также в методике определения группового состава органического вещества для выделения легкогидролизуемых соединений, а $\mathrm{H}_{2} \mathrm{SO}_{4}$ - для выделения трудногидролизуемых [7, 8]. Кроме того, при выщелачивании также удаляются водорастворимые органические соединения. Уже было отмечено, что $\delta^{13} \mathrm{C}$ органического вещества почвы изменяется после обработки $\mathrm{HCl}$ [10], и предлагались альтернативные методы удаления карбонатов [11]. В процессе декарбонатизации разница в значении $\delta^{13} \mathrm{C}$ может изменяться от 1.5 [12] до 7 \% $[12,13]$, что затрудняет интерпретацию полученных данных. Такого рода результаты могут возникать при интерференции сигналов искомого $\delta^{13} \mathrm{C}_{\text {карб }}$ от чистого карбоната и $\delta^{13} \mathrm{C}_{\text {орг }}$, который может образоваться в результате реакции органических соединений с $\mathrm{H}_{3} \mathrm{PO}_{4}$ [14], особенно интенсивного при повышенных температурах ( 70-90 $\left.{ }^{\circ} \mathrm{C}\right)$ реакции.

Одним из эффективных [5] и популярных реагентов, используемых для удаления органического углерода, является перекись водорода, однако для полного окисления органики недостаточно использования только этого реагента. При мокром озолении органического вещества или нефтей применяют кислоты $\left(\mathrm{HNO}_{3}\right)$, микроволновое разложение и т. д. [15], так как перекись водорода не удаляет органическое вещество полностью. Поэтому применяют $\mathrm{NaOCl}$, сухое озоление и т. д. Все перечисленные методы имеют свои ограничения [14].

Осадки озер содержат климатическую летопись, информацию об изменении глубины водоема, физико-химических характеристик растворов и условий формирования, данные о микробиальной активности, а осадки озер вулканических областей еще и информацию о ближайших извержениях. Осадки континентальных водоемов зачастую содержат карбонаты, очень различные по минеральному составу $[16,17]$. В случае одновременного нахождения в породе карбонатов различного состава используют методики селективного разложения. Например, применяется метод, учитывающий снижение растворимости карбонатных фаз в $\mathrm{H}_{3} \mathrm{PO}_{4}$. Разложение карбонатов проводится при температуре $70{ }^{\circ} \mathrm{C}$. Считается, что первая порция $\mathrm{CO}_{2}$, выделившаяся в течение 2 ч, соответствует кальциту; вторая (в течение 24 ч) - доломиту/анкериту; третья (в течение 7 дней) - сидериту и родохрозиту [18].

Несмотря на значительное количество исследований, к настоящему времени, по мнению Key Jr. М.M. и соавторов [5], не выработана общепринятая методика предварительной очистки образцов для анализа $\delta^{13} \mathrm{C}$ и $\delta^{18} \mathrm{O}$. Возможно, это связано с недоучетом таких фундаментальных факторов, как структурно-химическое разнообразие органики, участие матрицы в генерации

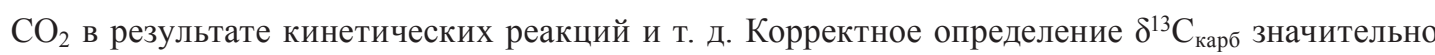
усложняется при повышении отношения $\mathrm{C}_{\text {орг }} / \mathrm{C}_{\text {карб}}$, что характерно для озерных осадков. Данное исследование представляет предварительные результаты изучения изменений $\delta^{13} \mathrm{C}$ в донных осадках термального озера при последовательном разложении $\mathrm{H}_{3} \mathrm{PO}_{4}$ в течение 2 ч, 24 ч и 7 дней. На примере отдельных образцов показано изменение $\delta^{13} \mathrm{C}$ во времени и после обработки $\mathrm{HCl}$ и $\mathrm{H}_{2} \mathrm{O}_{2}$. 


\section{Объект исследования}

Кальдера вулкана Узон является одной из пяти крупных кальдерных структур ВосточноКамчатского пояса и представляет западную (преобладающую) часть Узон-Гейзерной депрессии $[15,16,19]$. Озеро Фумарольное (N54³0'7.40" Е15959'16.85") образовалось на месте нескольких крупных фреатических воронок (рис. 1). На дне и в стенках воронок происходит разгрузка перегретых $\mathrm{Na}-\mathrm{Cl}$ вод. Большая группа источников сосредоточена на площадке Грязевой (озерко IV).

Разрез донных отложений озерка IV оз. Фумарольное очень неоднороден по составу, что свидетельствует о разнообразии и временной изменчивости физико-химических параметров обстановки в процессе его формирования. На основании изучения минерального состава сделан вывод о том, что изначально озерко IV представляло собой грязевой котел с сульфидсодержащими растворами. Затем при снижении уровня воды и выведении донных отложений на поверхность произошло их окисление. Последовавший фреатический взрыв привел к перекрытию окисленных отложений восстановленным веществом нижних горизонтов котла. Далее обстановка осадконакопления сначала соответствовала источнику с развивающимся вокруг грифона циано-бактериальным сообществом, затем сменилась обстановкой мелководного озерка, аналогичной современной. В осадке наблюдаются два слоя пирокластического материала от извержений недалеко расположенных вулканов. Осадок в верхней части сложен преимущественно диатомовыми илами с большим количеством глинистых минералов (рис. 2) [19]. В веществе донного осадка присутствует как органическое вещество, так и небольшое количество кальцита, сформировавшегося в узких ( 2 cм) горизонтах и составляющего в них до $15-18$ мас\%. Механизм формирования кальцита и источник углерода в нем остается дискуссионным, поскольку рН поверхностной воды колеблется от 4 до 5.5, при котором формирование карбона-

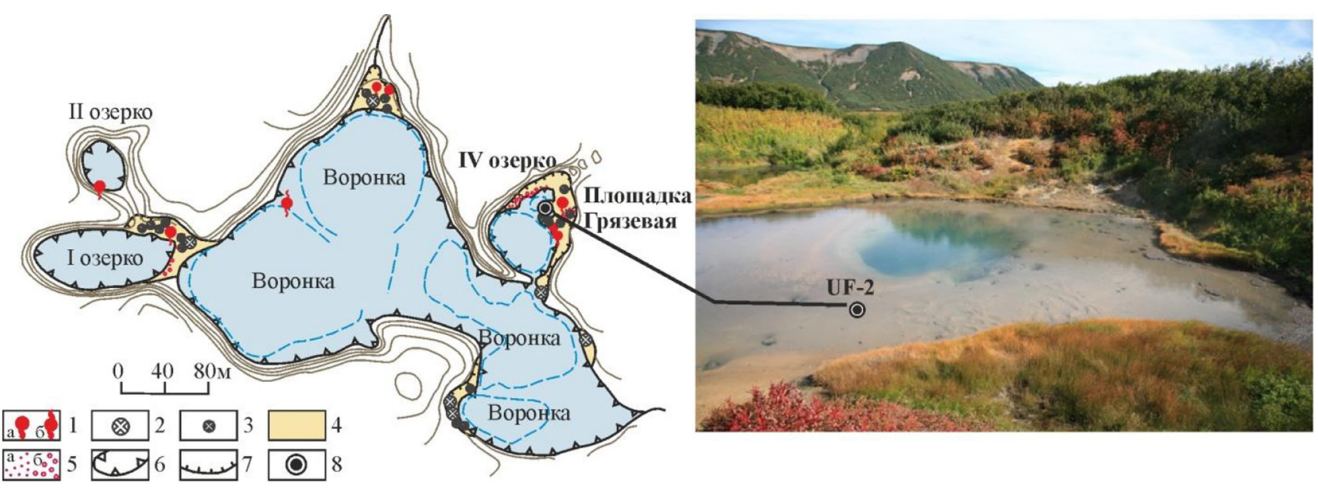

Рис. 1. Схема озера Фумарольное, береговых термальных площадок [по 16, с дополнениями] и место отбора колонки донного осадка: 1 - термальные источники (а - водяные воронки с видимым стоком, б выходы из трещины или высачивания); 2 - водяной бессточный котел; 3 - грязевой котел; 4 - парящие площадки; 5 - мелкие кипящие грифоны (а - мелкие водяные котлы, б - грязевые котлы); 6 - контур водной поверхности озера; 7 - контур термальных площадок; 8 - место отбора колонки донных отложений

Fig. 1. Schematic plan of the Lake Fumarolnoe and thermal sites on its shores [according to 16, with additions], and the sampling point of the bottom sediment core. Arbitrary notes: (1) thermal springs: (a) water craters with visible downf low, (b) outlets from a crack or an outcrop; (2) endorheic water pot; (3) mud pot; (4) streaming sites; (5) small boiling gryphons: (a) small water pots, (b) mud pots; (6) contour of the lake water surface; (7) contours of thermal sites; (8) sampling point of the bottom sediment core 


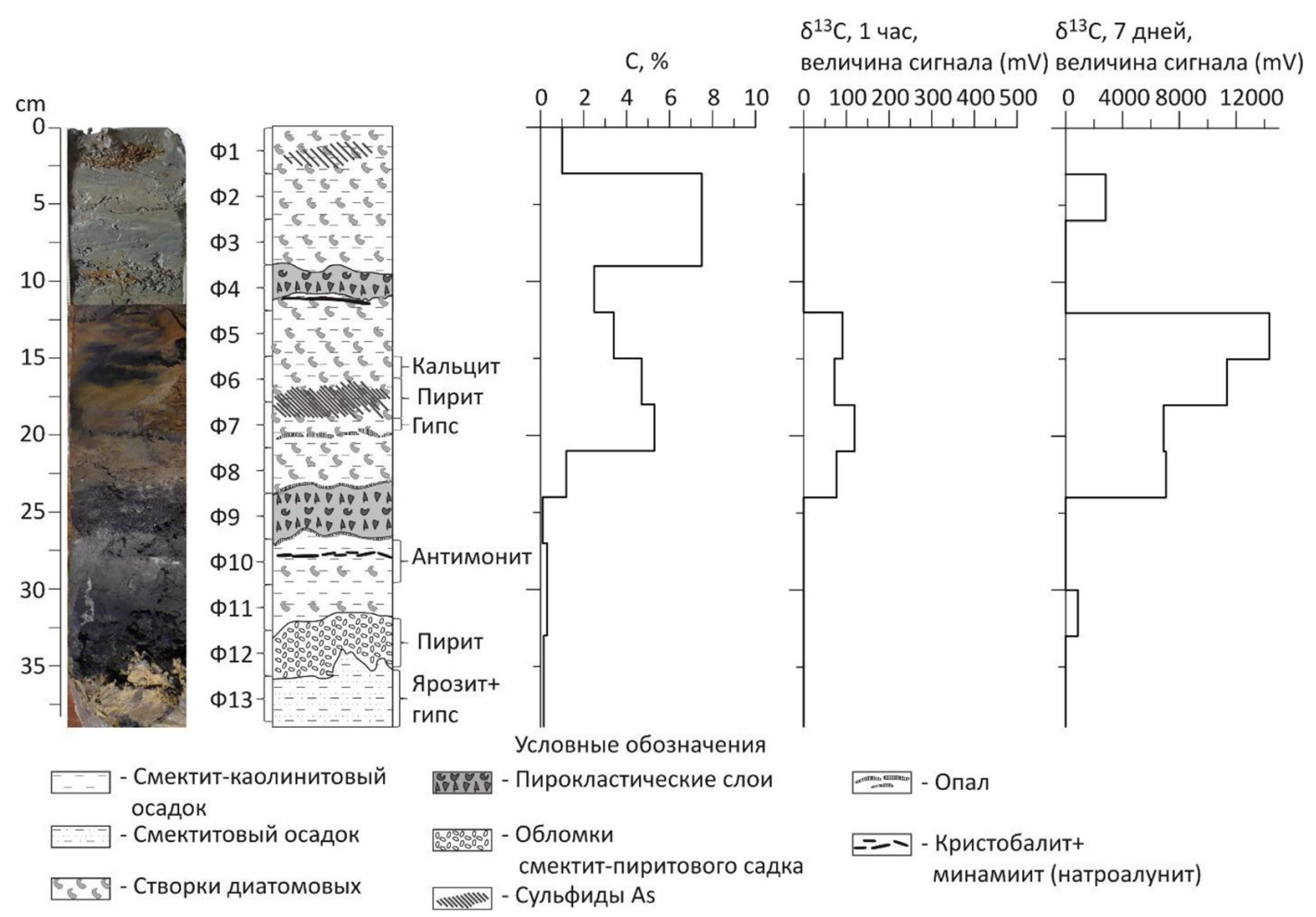

Рис. 2. Фотография и схема колонки донного осадка IV озерка оз. Фумарольное с указанием горизонтов отложения минералов, распределением углерода и величины сигнала $(\mathrm{mV})$ при анализе $\delta^{13} \mathrm{C}$

Fig. 2. Imaged and schematic representation of the bottom sediment core of the minor lake IV (Lake Fumarolnoe), with indicated horizons of deposited minerals, distribution of carbon and signal magnitude (mV) obtained during the analysis of $\delta^{13} \mathrm{C}$

та возможно главным образом при участии микроорганизмов [20]. В данной работе представлены результаты методических исследований особенностей определения изотопного состава углерода карбонатов и органического вещества в донных отложениях оз. Фумарольное. Для сравнения были взяты также образцы торфа из ореола рассеяния Урского хвостохранилища, заведомо не содержащие карбонатов и имеющие $\mathrm{pH}$ поровых растворов $<3$ [8].

\section{Методы исследования и образцы}

Колонка осадка (39 см) отобрана недалеко от берега (N54³0'7.40" E15959'16.85") вблизи небольшой воронки (рис. 2) с помощью цилиндрического пробоотборника из нержавеющей стали с вакуумным затвором конструкции НПО «Тайфун» (диаметр 82 мм, длина 40 см). Верхние жидкие, насыщенные водой, слабо консолидированные слои осадка (0-10 см) опробованы дополнительно с применением алюминиевого цилиндра. Вещество колонки на месте упаковывали в герметичную пленку, доставляли в лабораторию [19].

В потоке рассеяния Урского хвостохранилища были отобраны две пробы (массой 3-4 кг) органосодержащего вещества болотных кочек, относящихся к осоковому типу. Отбор проб производился на двух участках: ближняя зона потока рассеяния, покрытая отходами переработки первичных руд, на расстоянии 10 м от отвала (образец NOM-I); ближняя зона пото- 
ка рассеяния, покрытая отходами руд зоны окисления на расстоянии 12 м от отвала (образец NOM-II). Образцы взяты на глубине 30 см от поверхности, были помещены в пластиковые контейнеры с герметично закрывающейся крышкой и таким образом транспортировались в лабораторию [8].

Главные минералы, слагающие осадок оз. Фумарольное, были диагностированы с помощью рентгенофазового анализа (дифрактометр ДРОН 4, Си-анод) в ИГМ СО РАН. Состав и микроморфология минералов исследованы на сканирующем электронном микроскопе MIRA 3 LMU (TescanOrsayHolding) с системами микроанализа AztecEnergy/INCA Energy 450+ XMax 80 и INCAWave 500 (Oxford Instruments Nanoanalysis Ltd), позволяющими изучать наноразмерные частицы.

Содержание углерода определяли на CHNS-анализаторе varioMICROcube фирмы Elementer (Германия).

Фазовый состав кристаллических веществ и структурное состояние исследуемых объектов определяли методом порошковой рентгеновской дифрактометрии, которая также позволяет устанавливать количественные соотношения фаз, характеристики тонкой кристаллической структуры и кристаллохимические особенности дисперсных большей частью плохо окристаллизованных минералов. Рентгеновские исследования проводили на порошковом дифрактометре ARLX'TRA фирмы «ThermoFisherScientific (Ecublens) SARL», Швейцария, (излучение $\mathrm{Cu} K_{\alpha}$ ). Дифракционные картины отсканированы в диапазоне $2 \theta$ от $2^{\circ}$ до $55^{\circ}$ с шагом $0.05^{\circ}$, время сканирования в точке 5 с. Для регистрации карбонатов была проведена съемка дифрактограмм в диапазоне углов $2 \theta$ от $28^{\circ}$ до $34^{\circ}$ градусов с шагом $0.01^{\circ}$, время сканирования в точке $10 \mathrm{c}$.

Диагностика состояния минеральных объектов (аморфного и кристаллического), определение формы вхождения и типа «воды» в них проведены методом ИК-спектроскопии. Спектры записывались на ИК Фурье-спектрометре VERTEX70 FTIR фирмы Брукер. Образцы для ИК-спектроскопии готовили методом прессования таблеток с $\mathrm{KBr}$. Спектры матрицы $\mathrm{KBr}$ и атмосферы вычитали из регистрируемого спектра в программном пакете OPUS. Для удаления кристаллизационной воды и уточнения природы ОН колебаний в ИК-спектре была проведена термическая обработка образцов в таблетках $\mathrm{KBr}$ до $400^{\circ} \mathrm{C}$ в течение 30 мин.

Изначально $\delta^{13} \mathrm{C}$ определялось во всех пробах колонки донного осадка оз. Фумарольное без обработки реагентами. Для исследований влияния реагентов на изменение $\delta^{13} \mathrm{C}$ были выбраны образцы Ф6 и Ф11 из колонки оз. Фумарольное и образцы NOM-I и NOM-II из потока рассеяния Урского хвостохранилища. Вещество в количестве 0.5 г помещали в тефлоновые стаканчики и малыми порциями добавляли $10 \% \mathrm{HCl}$ в количестве 3 мл. Вещество нагревали, не доводя до кипения, в течение 30 мин до прекращения видимой реакции, затем остужали и промывали дистиллированной водой. Вещество отделяли от раствора центрифугированием и сушили. Сухой остаток взвешивали для определения потерь. В параллельной пробе 0.5 г вещества помещали в тефлоновые стаканчики и малыми порциями добавляли $30 \% \mathrm{H}_{2} \mathrm{O}_{2}$ в количестве 6 мл; нагревали, не доводя до кипения в течение 1 ч, добавляя $\mathrm{H}_{2} \mathrm{O}_{2}$ до прекращения видимой реакции; затем остужали и промывали дистиллированной водой. Вещество отделяли от раствора центрифугированием. Сухой остаток взвешивали.

Для анализа $\delta^{13} \mathrm{C}$ и $\delta^{18} \mathrm{O}$ в различных карбонатах используется дифференциальное по времени разложение в зависимости от растворимости минерала [18]. Для наиболее распространен-

$$
-423-
$$


ных в осадках смесей карбонатов - кальцита, доломита-анкерита, сидерита - выбрана следующая последовательность и длительность реакции $\mathrm{H}_{3} \mathrm{PO}_{4}$ : измерение через 2 ч реакции, продувка; измерение через 24 ч, продувка; измерение через 7 дней. Изотопный состав $\delta^{13} \mathrm{C}$ и $\delta^{18} \mathrm{O}$ в карбонатах и $\delta^{13} \mathrm{C}$ органического вещества определялся на масс-спектрометре FINNIGAN MAT-253 с приставкой GasBench II для анализа изотопов углерода в карбонатах в проточном (чистый $\mathrm{He)} \mathrm{режиме} \mathrm{и} \mathrm{с} \mathrm{приставкой} \mathrm{Flash} \mathrm{EA} \mathrm{1112.} \mathrm{Изотопные} \mathrm{значения} \delta^{13} \mathrm{C}$ приводятся относительно стандарта V-PDB. Точность определения $\delta^{13} \mathrm{C}$ составляла $\pm 0.1 \%$, $\delta^{18} \mathrm{O} \pm 0.1 \%$.

\section{Результаты и обсуждение}

Донные отложения оз. Фумарольного представляют слоистые осадки. Слои различаются по цвету, плотности, гранулометрическому и минеральному составу (рис. 2) [19]. Основная часть разреза сложена преимущественно каолинитом (преобладает) и смектитом, створками диатомовых водорослей и пиритом. В веществе встречаются обломки вулканических пород и отдельные минералы, из которых рентгенофазовым анализом надежно диагностируются плагиоклаз, кварц, небольшое количества цеолитов и минералы группы ярозита. Пирит в виде фрамбоидов и россыпи мелких кристаллов распределен в веществе неравномерно. Некоторые интервалы обогащены натечным пиритом, который отличается повышенными содержаниями As. Два интервала обогащены сульфидами мышьяка (реальгар и/или аурипигмент) (рис. 2). Среди мышьяковых минералов установлено повышенное содержание пирита и ниже расположен слой с высоким содержание гипса.

Отдельно следует отметить наличие слоев, сложенных преимущественно пирокластическим материалом. Доминируют обломками плагиоклазовых пород, часто со значительным количеством Ті-магнетита. Наблюдаются крупные (200-300 мкм) кристаллы пироксена. В веществе также установлено значительно количество фрамбоидального пирита, небольшое количество створок диатомовых водорослей, смектита, каолинита и цеолита. Под каждым пирокластическим слоем обнаружены плотные пластинчатые выделения, состоящие из кристобалита и минамиита (современное название минерала - натроалунит). Под вторым пирокластическим слоем наблюдается слой, обогащенный сферолитами антимонита. Нижняя часть разреза обогащена пиритом, а ниже 35 см - ярозитом (рис. 2).

Кальцит в разрезе установлен минералогическими методами только в единственном слое (Ф6), выше нижнего слоя, обогащенного сульфидами мышьяка. Минерал наблюдается при исследовании образцов на сканирующем микроскопе в виде мелких (не более 50 мкм) агрегатов.

Содержание углерода в разрезе колеблется от 0.15 до 7.5 \% (рис. 2, табл. 1), и самые высокие содержания установлены в верхней части колонки. На уровне первого пирокластического слоя содержание снижается до $2.5 \%$, между пирокластическими слоями увеличивается максимум до $5.3 \%$ и во втором пирокластическом слое составляет только $0.1 \%$, не превышая ниже по разрезу $0.3 \%$.

Анализ изотопов углерода в колонке донных отложений оз. Фумарольное показал, что при последовательном выщелачивании $\mathrm{H}_{3} \mathrm{PO}_{4}$ вещества, не обработанного реагентами, $\mathrm{CO}_{2}$ выделялся в небольшом количестве (после 2 ч обработки) из материала, расположенного в узком интервале, между двумя пепловыми слоями (Ф5-Ф8) и на порядок больше после 7 дней обработки (рис. 2). $\delta^{13} \mathrm{C}_{2}$ часа увеличивается вниз по разрезу от $-32.1 \%$ в слое Ф5 до $-30.7 \%$ в слое 
Таблица 1. Содержание углерода (C, мас\%), $\delta^{13} \mathrm{C}(\%)$ и в $\delta^{18} \mathrm{O}(\%)$ в $\mathrm{CO}_{2}$, выделившемся при разложении осадка оз. Фумарольное ортофосфорной кислотой $\left(\mathrm{H}_{3} \mathrm{PO}_{4}\right)$

Table 1. The content of carbon $(\mathrm{C}, \mathrm{wt} \%), \delta^{13} \mathrm{C}(\%)$ and $\delta^{18} \mathrm{O}(\%)$ in $\mathrm{CO}_{2}$ released during the decomposition of Lake Fumarolnoe sediment from phosphoric acid $\left(\mathrm{H}_{3} \mathrm{PO}_{4}\right)$

\begin{tabular}{|c|c|c|c|c|c|c|c|c|}
\hline \multirow{2}{*}{$\begin{array}{l}\text { Номер } \\
\text { пробы }\end{array}$} & \multirow{2}{*}{$\begin{array}{c}\text { Интервал, } \\
\text { см }\end{array}$} & \multirow{2}{*}{$\mathrm{C}, \%$} & Сигнал & $\delta^{13} \mathrm{C}$ & $\delta^{18} \mathrm{O}$ & Сигнал & $\delta^{13} \mathrm{C}$ & $\delta^{18} \mathrm{O}$ \\
\hline & & & \multicolumn{3}{|c|}{1 ч } & \multicolumn{3}{|c|}{7 дней } \\
\hline$\Phi 2$ & $3-6$ & 7.5 & & & & 2816 & -28.5 & 11.4 \\
\hline$\Phi 5$ & $12-15$ & 3.4 & 91 & $-32.1 \pm-0.4$ & $7.2 \pm 0.1$ & 14329 & -32.3 & 10.0 \\
\hline$\Phi 6$ & $15-18$ & 4.7 & 72 & $-31.5 \pm 0.3$ & $7.5 \pm 0.3$ & 11348 & -31.9 & 9.5 \\
\hline$\Phi 7$ & $18-21$ & 5.3 & 119 & $-31.1 \pm-0.1$ & $8.0 \pm 0.5$ & 6887 & -31.2 & 10.5 \\
\hline Ф8 & $21-24$ & 1.2 & 77 & $-30.7 \pm-0.5$ & $8.7 \pm-0.3$ & 7067 & -31.3 & 10.5 \\
\hline$\Phi 11$ & $30-33$ & 0.3 & & & & 852 & -24.7 & 12.2 \\
\hline
\end{tabular}

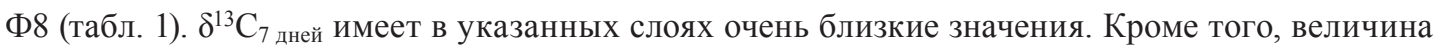
$\delta^{13} \mathrm{C}_{7}$ дней зафиксирована также и в слоях $\Phi 2$ и $Ф 11$, где значения заметно отличаются и составляют -28.5 и $-24.7 \%$ соответственно. В слое Ф6 минералогическими методами был выявлен кальцит, однако данные определения $\delta^{13} \mathrm{C}$ не выделяют данный слой из выше- и нижележащих (табл. 1).

После обработки вещества пробы $\Phi 6 \mathrm{H}_{2} \mathrm{O}_{2}$ в течение 2 ч выделения $\mathrm{CO}_{2}$ не установлено (табл. 2). После обработки $\mathrm{H}_{2} \mathrm{O}_{2}$, через 24 ч зафиксировано выделение $\mathrm{CO}_{2}$ в небольшом количе-

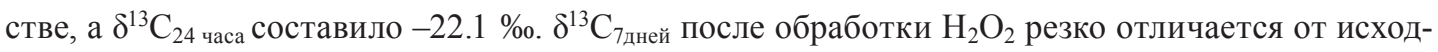

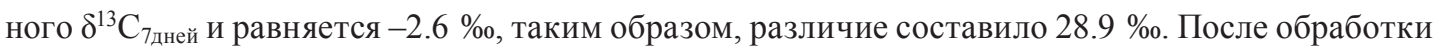
пробы Ф6 $\mathrm{HCl}$ значения $\delta^{13} \mathrm{C}_{2 \text { часа }}, \delta^{13} \mathrm{C}_{24 \text { часа }}$ и $\delta^{13} \mathrm{C}_{7 \text { дней }}$ оказались ближе значениям, установленным в необработанном веществе, и составили $-30.4,-30.3$ и $-28.3 \%$, но тем не менее через 2 и 24 ч выше на $1.1 \%$, а через 7 дней - на $3.2 \%$. При этом $\delta^{13} \mathrm{C}_{\text {орг, }}$ полученное после окисления кислородом, составляет $-29.9 \%$, следовательно, $\mathrm{CO}_{2}$, выделяющийся при взаимодействии $\mathrm{H}_{3} \mathrm{PO}_{4}$ с веществом, имеет чуть более легкий изотопный состав углерода, чем органическое вещество в целом (табл. 2).

В необработанном образце Ф11 выделение $\mathrm{CO}_{2}$ при реакции с $\mathrm{H}_{3} \mathrm{PO}_{4}$ было установлено через 7 дней и $\delta^{13} \mathrm{C}$ составило $-24.7 \%$ (табл. 2). После обработки $\mathrm{H}_{2} \mathrm{O}_{2}$ в течение 2 ч выделение $\mathrm{CO}_{2}$ не установлено. Но в веществе, обработанном $\mathrm{H}_{2} \mathrm{O}_{2}$, через 24 ч выделился $\mathrm{CO}_{2}$ с $\delta^{13} \mathrm{C}-10.3 \%$,

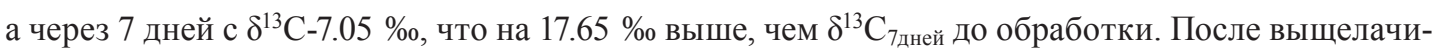
вания вещества $\mathrm{HCl}$ значение $\delta^{13} \mathrm{C}_{24}$ часа составило $-15.8 \%$, а $\delta^{13} \mathrm{C}_{7-\text { дней }}--18.9 \%$, что на $5.8 \%$

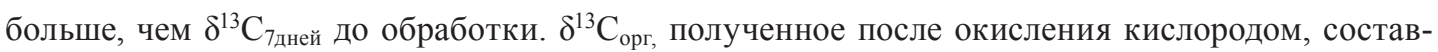
ляет $-28.2 \%$, что очень отличается от значений $\delta^{13} \mathrm{C}$, полученных при выщелачивании $\mathrm{H}_{3} \mathrm{PO}_{4}$ (табл. 2).

Данные о изотопном составе углерода, полученные после обработки вещества $\mathrm{H}_{2} \mathrm{O}_{2}$, могут быть интерпретированы в пользу присутствия в веществе карбонатов, более устойчивых, чем кальцит, если пользоваться методикой последовательной экстракции [18]. Поэтому были предприняты дополнительные исследования на примере образца Ф6. В этом горизонте установлен кальцит и можно было бы ожидать присутствие и других карбонатов.

$$
-425-
$$


Таблица 2. Содержание углерода $\left(\mathrm{C}\right.$, мас\%), $\delta^{13} \mathrm{C}(\%)$ в $\mathrm{CO}_{2}$, выделившемся при разложении осадка оз. Фумарольное ортофосфорной кислотой $\left(\mathrm{H}_{3} \mathrm{PO}_{4}\right)$ и торфяного вещества из потока рассеяния Урского хвостохранилища без обработки реагентами и после выщелачивания перекисью водорода $\left(+\mathrm{H}_{2} \mathrm{O}_{2}\right)$ и соляной кислотой $(+\mathrm{HCl})$; и $\delta^{13} \mathrm{C}(\%)$ в $\mathrm{CO}_{2}$ в веществе образцов при окислении кислородом $\left(\mathrm{O}_{2}\right)$

Table 2. The content of carbon $(\mathrm{C}, \mathrm{wt} \%), \delta^{13} \mathrm{C}(\%)$ in $\mathrm{CO}_{2}$ released during the decomposition of the sediment of the Lake Fumarolic orthophosphoric acid $\left(\mathrm{H}_{3} \mathrm{PO}_{4}\right)$ and peat matter from the dispersion train of the Ursk tailing dump without treatment with reagents and after leaching with hydrogen peroxide $\left(+\mathrm{H}_{2} \mathrm{O}_{2}\right)$ and hydrochloric acid $(+\mathrm{HCl})$; and $\delta^{13} \mathrm{C}(\%)$ in $\mathrm{CO}_{2}$ in the sample during oxidation with oxygen $\left(\mathrm{O}_{2}\right)$

\begin{tabular}{|c|c|c|c|c|c|}
\hline № образца (потери,\%) & $\mathrm{C}, \%$ & $\begin{array}{c}\text { Метод } \\
\text { определения }\end{array}$ & Время & $\begin{array}{c}\text { Величина } \\
\text { сигнала, } \mathrm{mV}\end{array}$ & $\delta^{13} \mathrm{C}$ \\
\hline \multirow{2}{*}{$\Phi 6$} & \multirow{2}{*}{4.7} & $\mathrm{H}_{2} \mathrm{PO}_{4}$ & $2 ч$ & 72 & -31.5 \\
\hline & & $-/ /-$ & 7 дней & 11348 & -31.9 \\
\hline \multirow{3}{*}{$\Phi 6+\mathrm{H}_{2} \mathrm{O}_{2}(41)$} & \multirow{3}{*}{ н.д. } & $-/ /-$ & $2 ч$ & нет сигнала & - \\
\hline & & $-/ /-$ & 24 ч & 254 & -22.1 \\
\hline & & & 7 дней & 298 & -2.6 \\
\hline \multirow{4}{*}{$\Phi 6+\mathrm{HCl}(25)$} & \multirow{4}{*}{ н.д. } & $-/ /-$ & $2 ч$ & 98 & -30.4 \\
\hline & & $-/ /-$ & 24 ч & 627 & -30.3 \\
\hline & & & 7 дней & 626 & -28.3 \\
\hline & & $\mathrm{O}_{2}$ & & 4418 & -29.9 \\
\hline \multirow{2}{*}{$\Phi 11$} & \multirow{2}{*}{0.3} & $\mathrm{H}_{2} \mathrm{PO}_{4}$ & $2 ч$ & нет сигнала & - \\
\hline & & $-/ /-$ & 24 ч & 852 & -24.7 \\
\hline \multirow{3}{*}{$\Phi 11+\mathrm{H}_{2} \mathrm{O}_{2}(23)$} & \multirow{3}{*}{ н.д. } & $-/ /-$ & $2 ч$ & нет сигнала & - \\
\hline & & $-/ /-$ & 24 ч & 83 & -10.3 \\
\hline & & & 7 дней & 220 & -7.05 \\
\hline \multirow{4}{*}{$\Phi 11+\mathrm{HCl}(17)$} & \multirow{4}{*}{ н.д. } & $-/ /-$ & $2 ч$ & нет сигнала & - \\
\hline & & $-/ /-$ & 24 ч & 98 & -15.8 \\
\hline & & & 7 дней & 222 & -18.9 \\
\hline & & $\mathrm{O}_{2}$ & & 1960 & -28.2 \\
\hline \multirow{4}{*}{ NOM-I } & \multirow{4}{*}{36.8} & $\mathrm{H}_{2} \mathrm{PO}_{4}$ & 2 час & 721 & -28.2 \\
\hline & & $-/ /-$ & 24 часа & 2578 & -28.8 \\
\hline & & $-/ /-$ & 7 дней & 2844 & -26.3 \\
\hline & & $\mathrm{O}_{2}$ & & 5895 & -26.9 \\
\hline \multirow{4}{*}{ NOM-II } & \multirow{4}{*}{36.4} & $\mathrm{H}_{2} \mathrm{PO}_{4}$ & $2 ч$ & 681 & -28.8 \\
\hline & & $-/ /-$ & 24 ч & 1828 & -27.2 \\
\hline & & $-/ /-$ & 7 дней & 1896 & -23.8 \\
\hline & & $\mathrm{O}_{2}$ & & 14182 & -26.7 \\
\hline
\end{tabular}

Примечание: н. д. - нет данных.

По данным дифрактометрии и ИК-спектроскопии (рис. 3, 4), в образце Ф6 зафиксированы смектит (+органика), каолинит, плагиоклаз, гипс. Рефлексы смектита характерны для напитанных органикой образцов [21]. Для дополнительной регистрации карбонатов была проведена съемка дифрактограммы в диапазоне углов 2 тета 28-34 градусов с шагом $0.01^{\circ}$ (рис. 3). Наблюдаемые рефлексы были малоинтенсивными, на уровне фона, предполагаемые рефлексы карбонатов совпадали с рефлексами каолинита, плагиоклаза, гипса, смектита. Таким образом, диагностировать присутствия карбоната в веществе не удалось. 

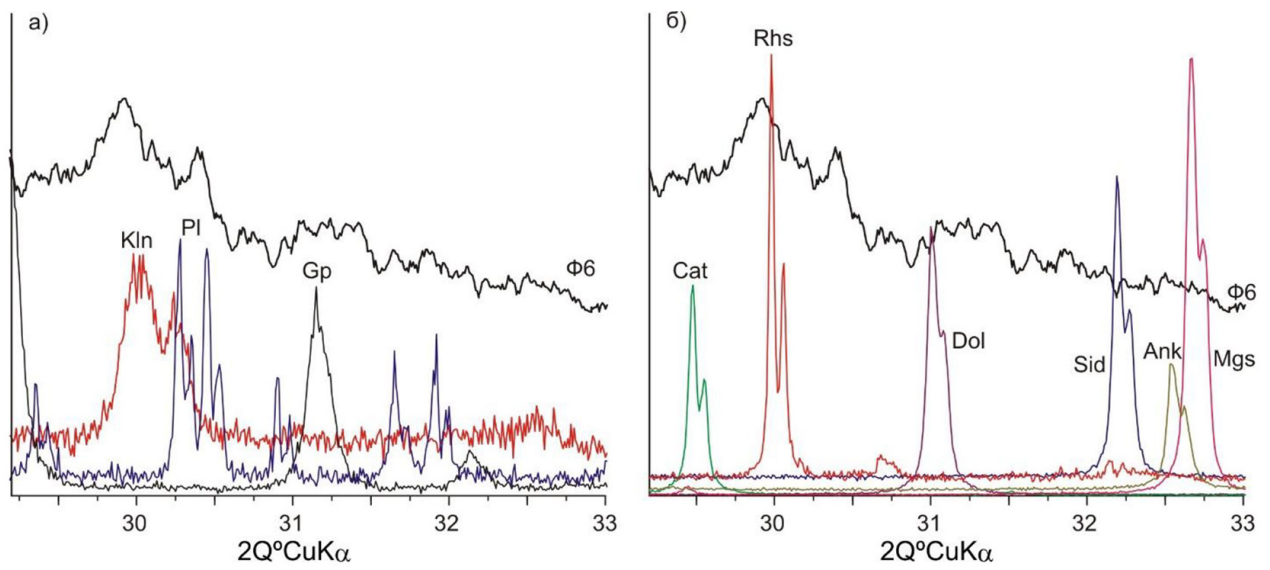

Рис. 3. Фрагменты дифрактограмм образца Ф6 в области основных рефлексов карбонатов и (а) эталонные дифрактограммы минералов, встречающихся в осадке (Kln - каолинит; Gp - гипс; Pl - плагиоклаз), и (б) карбонатов (Cal - кальцит; Rhs - родохрозит; Dol - доломит, Sid - сидерит, Ank - анкерит, Mgs - магнезит)

Fig. 3. Fragments of diffractograms of sample F6 in the region of the main reflections of carbonates and (a) reference diffractograms of minerals occurring in the sediment (Kln - kaolinite; Gp - gypsum; Pl - plagioclase), and (b) carbonates (Cal - calcite; Rhs - rhodochrosite; Dol - dolomite, Sid - siderite, Ank - ankerite, Mgs magnesite)

ИК-спектр образца Ф6 приведен на рис. 4. Наблюдаемые полосы в спектрах являются характерными для каолинита и смектита $[21,22]$. В диапазоне волновых чисел $1400-1460 \mathrm{~cm}^{-1}-$ области основной полосы карбонатов - зарегистрировано небольшое плечо, которое могло бы указывать на незначительное следовое количество карбоната $<<1$ \% (рис. 4, вставка). Но данное плечо может быть обусловлено наличием органической компоненты. В диапазоне волновых чисел 1400-1800 см-1 регистрируются деформационные колебания ОН-групп около $1640 \mathrm{~cm}^{-1}$, деформационные колебания метиленовых и метильных групп в молекулах гуминовых кислот в области 1380-1480 см-1 , валентные колебания $\mathrm{C}=\mathrm{C}$-групп или Н-связанных карбонильных $\mathrm{C}=\mathrm{O}$-групп в области $1630 \mathrm{~cm}^{-1}$, а также валентные колебания карбоксильных групп $\mathrm{C}=\mathrm{O}$ при 1710 см$^{-1}$ [22-25]. Валентные колебания СН-групп зафиксированы при 2854, 2925 и $2962 \mathrm{~cm}^{-1}$ (плечо). Для уточнения природы ОН-колебаний был проведен отжиг в таблетке КВr при 400 ${ }^{\circ} \mathrm{C}$; помимо удаления кристаллизационной воды смектита был зафиксирован большой выход $\mathrm{CO}_{2}$ - полоса $2338 \mathrm{~cm}^{-1}$ (рис. 2, криая 2). При отжиге наблюдалось изменение соотношения полос валентных колебаний $(\mathrm{Si}, \mathrm{Al}), \mathrm{O}$, не характерное при более высокотемпературной термической обработке диатомей [26].

Для сравнения проведены эксперименты по выщелачиванию $\mathrm{H}_{3} \mathrm{PO}_{4}$ торфяного вещества Урского хвостохранилища. Тут природное детритовое вещество в течение более 80 лет контактировало с кислыми дренажными растворами и нахождение карбонатов исключено. При взаимодействии $\mathrm{H}_{3} \mathrm{PO}_{4}$ с веществом выделяется $\mathrm{CO}_{2}$ на всех этапах эксперимента - через 2 ч, 24 ч и 7 дней. Также установлено увеличение значения $\delta^{13} \mathrm{C}$ выделившегося $\mathrm{CO}_{2}$ в зависимости от времени взаимодействия с реагентом (табл. 2): NOM-I - c -28.2 до $-26.3 \%$; NOM-II - с -28.8 до $-23.8 \%$. При этом $\delta^{13}$ Сорг в обоих образцах составил $-26.9 \%$. 


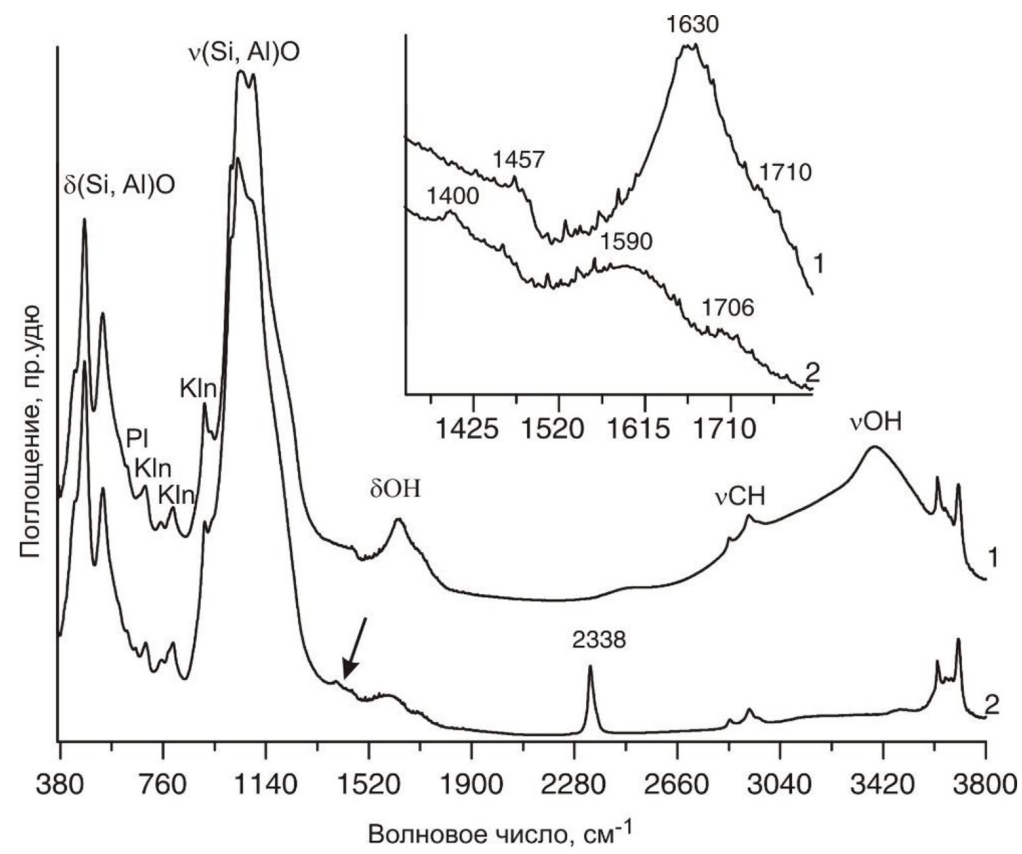

Рис. 4. Инфракрасные спектры образца Ф6: исходного (1) и отожженого в таблетке $\mathrm{KBr}$ при $400{ }^{\circ} \mathrm{C}(2)$. На вставке - фрагменты ИК- спектров в области валентных колебаний $\mathrm{CO}_{3}{ }^{2-}$ ионов, $\mathrm{C}=\mathrm{O}-, \mathrm{C}=\mathrm{C}$-связей и деформационных колебаний С-Н и О-Н связей

Fig. 4. Infrared spectra of sample F6: initial (1) and annealed in a $\mathrm{KBr}$ pellet at $400{ }^{\circ} \mathrm{C}(2)$. The inset shows fragments of IR spectra in the region of stretching vibrations of $\mathrm{CO}_{3}{ }^{2-}$ ions, $\mathrm{C}=\mathrm{O}-, \mathrm{C}=\mathrm{C}$-bonds and bending vibrations of $\mathrm{C}-\mathrm{H}$ and $\mathrm{O}-\mathrm{H}$ bonds

\section{Заключение}

В донных отложениях оз. Фумарольное без предварительной обработки вещества установлено выделение $\mathrm{CO}_{2}$ при реакции вещества с ортофосфорной кислотой преимущественно в осадке, расположенном между пепловыми слоями. $\delta^{13} \mathrm{C}$ двуокиси углерода совпадает с изотопным составом нефти кальдеры Узон. По данным Г. А. Карпова, признаки нефти в пределах кальдеры Узон установлены на трех термальных площадках оз. Фумарольное [15]. Нафтидопроявления кальдеры влк. Узон характеризуются тяжелыми малосмолистыми нефтями: в их составе преобладают углеводороды, причем насыщенных структур почти в два раза больше (57-58 \%), чем ароматических (30-32\%).

Очень важным и, возможно, диагностическим признаком является то, что при выщелачивании необработанного вещества, расположенного между пепловых слоев (рис. 2), изотопный состав углерода со временем почти не изменяется. Как показали эксперименты с выщелачиванием торфяного вещества, которое имеет сложный групповой состав (водорастворимые соединения - 20 \%, битумы 3-5 \%, фульвовые кислоты - 7.5-11\%, гуминовые кислоты - 30-35\%, легкогидролизуемые соединения - 3-6 \%, трудногидролизуемые соединения - 12\%, нерастворимый остаток - 15-18 \%), изотопный состав со временем выщелачивания становится более тяжелым.

Предварительная обработка вещества осадка соляной кислотой привела к заметному увеличению $\delta^{13} \mathrm{C}$. При использовании $\mathrm{HCl}$ из материала удаляются легкогидролизуемые и водо- 
растворимые вещества, которые, вероятно, имеют более легкий изотопный состав углерода. Но самые большие изменения изотопного состава были зафиксированы после обработки вещества перекисью водорода. В образцах Ф6 и Ф11, обработанных $\mathrm{H}_{2} \mathrm{O}_{2}$, через 2 ч выход $\mathrm{CO}_{2}$ не установлен. Но через 24 ч и 7 дней выделившийся $\mathrm{CO}_{2}$ имел намного более тяжелый изотопный состав углерода (табл. 2). Количество же выделяющегося $\mathrm{CO}_{2}$ значительно уменьшилось, о чем можно судить по снижению величины сигнала (табл. 2). Какие процессы приводят к такому резкому фракционированию изотопного состава углерода, еще предстоит выяснить.

Известно большое количество способов приготовления фосфорнокислых катализаторов, где используется ортофосфорная кислота. В качестве носителя предлагались пемзы, глинистые минералы, диатомит, цеолиты и т. д. При использовании в качестве носителя алюмосиликатов для большей эффективности его предварительно обрабатывают горячей серной кислотой. Для активации используется также и $\mathrm{HCl}$ [27]. Следовательно, минералы осадка в совокупности с ортофосфорной кислотой будут являться катализатором окисления органических соединений, а возможно, и более сложных превращений. Известно, что $\mathrm{CO}_{2}$ - продукт не только каталитического окисления углеводородов, но и синтеза [28]. Наиболее вероятным представляется механизм декарбоксилирования [29]. Следует также уточнить, что осадок содержит пирит, который окисляется под действием $\mathrm{H}_{2} \mathrm{O}_{2}$, и некоторое количество сульфатов железа, неизбежно сформировавшихся при высушивании и частичном окислении осадка. Следовательно, при выщелачивании подобного вещества будет происходить формирование реактива Фентона, который, как известно, не только способствует окислению органических соединений, но и участвует в более сложных реакциях.

Не до конца ясно, возможно ли присутствие в веществе осадка малых количеств устойчивых карбонатов, например магнезита. Или есть вероятность его формирования в ходе обработки вещества перекисью водорода? Важно, что при исследованиях изотопного состава в осадках не был диагностирован кальцит, хотя при отборе он присутствовал в колонке. Не исключено, что при хранении вещества и окислении тонкодисперсных сульфидов кислородом воздуха минерал мог разложиться при взаимодействии с сульфатными растворами с образованием гипса.

Таким образом, в изученном веществе донного осадка оз. Фумарольное $\mathrm{CO}_{2}$ выделяется из органического вещества при реакции с $\mathrm{H}_{3} \mathrm{PO}_{4}$ как до обработки $\mathrm{HCl}$ и $\mathrm{H}_{2} \mathrm{O}_{2}$, так и после нее. После обработки образцов $\mathrm{HCl}$ значения $\delta^{13} \mathrm{C}$ изменяются от 1 до $3 \%$, что вполне можно учесть при проведении исследований. Однако после обработки образцов $\mathrm{H}_{2} \mathrm{O}_{2}$ и реакции с $\mathrm{H}_{3} \mathrm{PO}_{4}$ изотопный сигнал появляется только при длительности реакции 24 ч и 7 дней, причем с резким изменением изотопного сигнала на величину до 26 \%о,, что указывает на существенную трансформацию С-содержащего остаточного после очистки вещества, и это необходимо учитывать при проведении С-О-изотопного анализа при повышенных температурах и длительной реакции.

\section{Благодарности / Acknowledgements}

Работа выполнена в рамках госзадания ИГМ СО РАН им. В.С. Соболева и в ЦКП Многоэлементных и изотопных исследований ИГМ СО РАН.

This work was carried out within the framework of the state assignment of the I.G. V.S. Sobolev and at the Center for Collective Use of Multielement and Isotope Research, IGM SB RAS. 


\section{Список литературы / References}

1. Галимов Э. М. Геохимия стабильных изотопов углерода. Москва: Недра, 1968. 226 с. [Galimov E. M. Geochemistry of stable carbon isotopes. Moscow: Nedra, 1968. 226 p. (In Russ.)]

2. Хёфс Й. Геохимия стабильных изотопов. М.: Мир. 1983. 200 с. [Hefs J. Geochemistry of stable isotopes. Moscow: Mir, 1983. 200 p. (In Russ.)]

3. McCrea J. M., On the Isotopic Chemistry of Carbonates and a Paleotemperature Scale. The Journal of chemical phesics 1950. Vol. 18(6), P. 849-857.

4. Epstein S., Buchsbaum R., Lowenstam HA., Urey HC. Revised carbonate-water isotopic temperature scale. Geol Soc Am Bull. 1953. Vol. 64(11), P. 1315-1326.

5. Key Jr M.M., Smith A.M., Phillips N.I., Jeffrey S. Forrester J.S. Effect of removal of organic material on stable isotope ratios in skeletal carbonate from taxonomic groups with complex mineralogies. Rapid Commun Mass Spectrom 2020. Vol. 34, P. 8901.

6. Midwood A. J. and Boutton T. W. Soil carbonate decomposition by acid has little effect on the $\mathrm{d}^{13} \mathrm{C}$ of organic matter. Soil Biol. Biochem 1998. Vol. 30, P. 1301-1307.

7. Taran O.P., Boltenkov V.V., Ermolaeva N.I., Zarubina E.Y., Delii I.V., Romanov R.E., Strakhovenko V.D. Relations between the Chemical Composition of Organic Matter in Lacustrine Ecosystems and the Genesis of Their Sapropel. Geochemistry International 2018. Vol. 56(3), P. 256-265.

8. Myagkaya I.N., Saryg-ool $\quad$ B. Yu., Surkov O.N., Zhmodik S.M., Lazareva E.V., Taran O.P. Natural Organic Matter from the Dispersion Train of Gold Sulfide Tailings: Fraction Compositions and Speciation of Elements. Geochemistry: Exploration, Environment, Analysis 2020. Vol. 21(1), geochem 2020-052.

9. Taran O. P., Skripnikov A. M., Ionin V. A., Kaigorodov K. L., Krivonogov S. K., Dobretsov N. N., Dobretsov V.N., Lazareva E.V., Kruk N.N. Composition and Concentration of Hydrocarbons of Bottom Sediments in the CHPP-3 Diesel-Fuel Spill Zone at AO NTEC (Norilsk, Arctic Siberia). Contemporary Problems of Ecology 2021. Vol. 14(4), P. 335-355.

10. Fernandes M. and Krull E. How does acid treatment to remove carbonates affect the isotopic and elemental composition of soils and sediments? Environ. Chem. 2008. Vol. 5, P. 33-39.

11. Ramnarine R., Voroney R.P., Wagner-Riddle C., Dunfield. K.E. Carbonate removal by acid fumigation for measuring the $\delta^{13} \mathrm{C}$ of soil organic carbon. Can. J. Soil Sci 2011. Vol. 91, P. 247-250.

12. Pasquier V., Sansjofre P., Lebeau O., Liorzou C., Rabineau M. Acid digestion on river influenced shelf sediment organic matter: Carbon and nitrogen contents and isotopic ratios. Rapid Communications in Mass Spectrometry 2018. Vol. 32(2), P. 86-92.

13. Brodie CR, Leng MJ, Casford J, Kendrick CP. Evidence for bias in C and N concentrations and $\delta^{13} \mathrm{C}$ composition of terrestrial and aquatic organic materials due to pre-analysis acid preparation methods. Chem. Geol. 2011. Vol. 282, P. 67-83.

14. Chaduteau C., Ader M., Lebeau O., Landais G., Busigny V. Organic matter removal for continuous flow isotope ratio mass spectrometry analysis of carbon and oxygen isotope compositions of calcite or dolomite in organic-rich samples. Limnology and Oceanography: Methods 2021. Vol. 9, P. 523-539.

15. Dobretsov N.L., Lazareva E.V., Zhmodik S.M., Bryanskaya A.V., et al. Geological, hydrogeochemical, and microbiological characteristics of the «oil site» of the Uzon caldera (Kamchatka). Russian Geology and Geophysics 2015. Vol. 56(1-2), P. 39-63. 
16. Вулканизм, гидротермальный процесс и рудообразование / Ред. С. И. Набоко. Л.: Недра, 1974. 178 с. [Volcanism, Hydrothermal Process and Ore Formation, L.: Nedra, 1974. 178 p. (In Russ.)]

17. Solotchina E. P., Solotchin P. A., Zhdanova A. N., Bezrukova E. V., Shtok O. Late pleistosteneholocene sedimentation in lakes of central Eransbaikalia: implications for climate and environment changes. Russian Geology and Geophysics 2018. Vol. 59(11), P. 1419-1432.

18. Al-Aasm I.S., Taylor B. E., South B. Chemical Geology 1990. Vol. 80, P. 119-125.

19. Kirichenko I. S., Lazareva E. V.,Zhmodik S. M., Belyanin D. K., Miroshnichenko L. V. Modern mineral formation in the thermal lake Fumarolnoe (the Uzona caldera, Kamchatka) is the key to paleoreconstruction. Geology of Ore Deposits 2019. Vol. 61(8), P. 1-9.

20. Лазарева Е. В., Анисимова Н. С., Брянская А. В., Огородникова О. Л., Жмодик С. М., Особенности минералообразования в микробных сообществах, развивающихся по изливу источника Термофильный (кальдера Узон, Камчатка). Труды Кроноцкого государственного биосферного заповедника. Вып. 2. Отв. ред. В. И. Мосолов. Петропавловск-Камчатский: Камчатпресс, 2012. C. 143-156. [Lazareva, E.V., Anisimova, N.S., Bryanskaya, A.V., Ogorodnikova, O.L., Zhmodik, S.M., Peculiarities of mineral formation in microbial communities in the Termofilny spring (Uzon caldera, Kamchatka), in: Mosolov, V.I. (Ed.), Trans. Kronotsky State Biospheric Reserve. Petropavlovsk-Kamchatskii: Kamchatpress, 2012. I. 2, P. 143-156. (In Russ.)]

21. Palchik N.A., Moroz T.N., Miroshnichenko L. V., Artamonov V.P. Crystal Chemistry of Carbonates and Clay Minerals from Bottom Sediments of Okhotskoe Sea as an Indicator of Climate Change. In: Votyakov S., Kiseleva D., Grokhovsky V., Shchapova Y. (eds) Minerals: Structure, Properties, Methods of Investigation. Springer Proceedings in Earth and Environmental Sciences. Springer, Cham. 2020. P. 161-168.

22. Орлов Д. С., Осипова Н.Н. Инфракрасные спектры почв и почвенных компонентов. М.: МГУ, 1988. 89 с. [Orlov DS, Osipova NN Infrared spectra of soils and soil components. Moscow: Moscow State University, 1988. 89 p. (In Russ.)]

23. Gostishcheva M. V.,Belousov M. V., Yusubov M. S.,Dmitruk S. E.,Ismatova R. R. Comparative IR spectral characteristics of humic acids from peats of different origin in the Tomsk area. Pharmaceutical Chemistry Journal 2009. Vol. 43(7), P. 418-421.

24. Ishiwatari R. Infrared absorption band at $1540 \mathrm{~cm}^{-1}$ of humic acid from a recent lake sediment. Geochemical Journal 1967. Vol. 1, P. 61-70.

25. Li L., Zhao Z., Huang W., Peng P., Sheng G., Fu J. Characterization of humic acids fractionated by ultrafiltration. Organic Geochemistry 2009. Vol. 35, P. 1025-1037.

26. Chaisena A., Rangsriwatananon K. Effects of thermal and acid treatments on some physicchemical properties of lampang diatomite. Suranaree J. Sci. Technol 2004. Vol.11, P. 289-299.

27. Далин М.А., Мамедова ВМ., Мангасарян Н. А., Левина Т. Я., Путникова Н. Т. Фосфорнокислые катализаторы в промышленных процессах переработки низкомолекулярных олефинов. Серия «Нефтехимия и сланцепереработка»/ ЦНИИТЭнефтехим. Москва, 1978. 30 с. [Dalin M. A., Mamedova VM., Mangasaryan N. A., Levina T. Ya., Putnikova N. T. Phosphate catalysts in industrial processes for the processing of low molecular weight olefins. Series «Petrochemistry and oil shale processing», 1978. 30 p. (In Russ.)] 
28. Кузнецов В.И. Развитие каталитического органического синтеза. М.: Наука, 1964. 400 c. [Kuznetsov V.I. Development of catalytic organic synthesis. Moscow: Science, 1964. 400 p. (In Russ.)]

29. Губен-Вейль. Методы органической химии. Том II. Издание 2-е, стереотипное. М.: Химия, 1967. 1032 c. [Guben-Weil. Methods of organic chemistry, Moscow, 1967. 1032 p. ((In Russ.)] 